\title{
Bovine Tuberculosis Policy in England: Would a Virtuous Government Cull Mr Badger?
}

\author{
Steven P. McCulloch ${ }^{1} \cdot$ Michael J. Reiss $^{2}$
}

Accepted: 31 July 2017/Published online: 28 August 2017

(C) The Author(s) 2017. This article is an open access publication

\begin{abstract}
Bovine tuberculosis (bovine TB) is the most important animal health and welfare policy issue in Britain. Badgers are a wildlife reservoir of disease, although the eight-year Independent Scientific Group (ISG) Randomised Badger Culling Trial concluded with a recommendation against culling. The report advised government that bovine TB could be controlled, and ultimately eradicated, by cattlebased measures alone. Despite the ISG recommendation against culling, the farming and veterinary industries continued to lobby government for a badger cull. The 2005-2010 Labour government followed the ISG advice and decided against a cull. The 2010-2015 Coalition and the 2015-present Conservative governments have followed a badger culling policy. This paper investigates whether a virtuous government would cull badgers. It provides an overview of virtue theory in the context of government animal health and welfare policy. Bovine TB and badger control policy options are then analysed in the context of the virtues of justice, wisdom, integrity, loyalty, curiosity, trust, empathy, compassion and aesthetics. Justice is the first virtue of government, and badger culling is seriously problematic from a virtue perspective given that five badgers are culled per cow that avoids slaughter as a result. Analysis based on other virtues strongly suggests that government should not cull badgers. The paper concludes that a virtuous government would not cull badgers as part of policy to control bovine TB in cattle.
\end{abstract}

Michael J. Reiss

m.reiss@ucl.ac.uk

Steven P. McCulloch

Steven.McCulloch@winchester.ac.uk

1 University of Winchester, Sparkford Road, Winchester SO22 4NR, UK

2 UCL Institute of Education, University College London, 20 Bedford Way, London WC1H 0AL, UK 
Keywords Animal health and welfare policy · Badger culling ·

Badger vaccination - Bovine tuberculosis · Evidence-based policy ·

Virtue theory

\section{Introduction}

Bovine tuberculosis (bovine TB) is a controversial animal health and welfare policy issue in Britain. The science, policy and politics of bovine TB and badger control are discussed in McCulloch and Reiss (2017a). In that paper, we argue that (1) Animal Welfare Impact Assessment (AWIA) and (2) independently conducted ethical analysis, using established moral frameworks, should be applied to animal health and welfare policy issues. AWIA is applied to bovine TB and badger control policy options in McCulloch and Reiss (2017b). This paper provides a virtue-based analysis of government policy on badger culling.

The first part of this paper provides a brief overview of bovine TB and badger control policy in England. The second part of the paper describes virtue-based theory and its application to government policy. In the third part, bovine TB and badger control policy is analysed in the context of virtue-based moral theory. In doing this we draw on a series of semi-structured interviews. The first author conducted these with animal health and welfare policy actors as part of a larger research project which this paper is based on. A total of 17 interviews were conducted in 2012 and 2013. Quotations from interviews are indicated by square brackets. Further details about the interviewing methodology can be found in McCulloch and Reiss (2017a). ${ }^{1}$

\section{Bovine TB and Badger Control Policy}

Bovine TB is the most economically important animal health and welfare issue in Britain. The incidence of bovine TB in cattle has been rising in recent decades and the disease is projected to cost government $£ 1$ billion over the next decade (Defra 2011c). The disease was nearly eradicated in the 1960s due to a strict attested herd scheme. In 1971, a dead badger in Gloucestershire was found to be infected with bovine TB. Since then, badgers have been culled in an effort to control the disease in cattle. Given the rising incidence of bovine TB and the uncertainty around the role of badgers as a wildlife reservoir of infection, the Independent Scientific Review Group (ISRG), chaired by Professor Krebs, recommended a field trial to determine the impact of badger culling (Krebs et al. 1997).

Based on the subsequent Randomised Badger Culling Trial (RBCT), the Independent Scientific Group (ISG) concluded that badger culling can provide no

\footnotetext{
${ }^{1}$ Interviewees included a former government minister, a retired Department for Environment, Food and Rural Affairs (Defra) civil servant, an Animal Health and Welfare Board of England (AHWBE) member, a former President of the British Cattle Veterinary Association (BCVA), a National Farmers Union (NFU) TB policy official and Professor John Bourne, the Chair of the Independent Scientific Group (ISG), which conducted the Randomised Badger Culling Trial (RBCT).
} 
meaningful contribution to disease control. It advised that the disease could be controlled and ultimately eliminated by cattle-based measures alone (Bourne et al. 2007a). Despite the ISG's findings, the subsequent King review found that badger culling could contribute to bovine TB control (King 2007). The 2005-2010 Labour government followed the ISG recommendation and rejected calls by the farming industry and veterinary profession for a badger cull. However, the 2010-2015 Coalition and the 2015-present Conservative governments have implemented a farmer-led badger cull. Pilot badger culls were conducted in Somerset and Gloucestershire in 2013 to assess the effectiveness, safety and humaneness of badger culling. The Independent Expert Panel (IEP) report found that the pilot culls failed the government's effectiveness and humaneness tests (IEP 2014). Despite this, the culls in Somerset and Gloucestershire have continued annually, with the fourth cull conducted in 2016. The badger cull has been rolled out in 2015 to North Dorset and a further seven areas in 2016 in the counties of Herefordshire, Gloucestershire, Cornwall, Devon and Dorset (Defra 2016).

\section{Virtue-Based Ethics}

\section{The Virtuous Person, Society and Government}

In virtue-based ethics, virtues play a central or independent role in right action. Three central concepts in virtue ethics are (1) virtue, (2) practical wisdom, and (3) eudaimonia. Eudaimonia can be roughly translated as happiness, flourishing or wellbeing. A virtue is a good, admirable or praiseworthy character trait. In contrast, a vice is a bad or unpraiseworthy character trait. Virtuous people possess and exercise the virtues, or certain character traits, such as benevolence, generosity, compassion, honesty and justice (Hursthouse 2013). Virtuous acts are therefore practised by virtuous persons, and we can extend this to say that a virtuous government will make virtuous policy, and a virtuous society will be ruled by and conform to virtuous laws.

\section{Virtue Theory Applied to Public Policy}

Since it is government that makes policy which impacts animals, the important question is what sort of policy would a virtuous government make? The influential political philosopher John Rawls famously wrote "Justice is the first virtue of social institutions" (Rawls 1971, p. 3). Raphael claims that justice is to do with fairness, or giving "to each his due" (Raphael 2001, p. 183).

Theories of justice can be based on (1) maximising welfare, (2) respecting freedom, or (3) on some conception of the good (Sandel 2010). These three conceptions roughly map onto utilitarianism, rights-based and virtue theory. Should sentient animals such as cattle and badgers be treated according to principles of justice? Arguably, sentiency - the capacity to feel pleasure and pain and have a subjective experiential life-suggests that sentient animals ought to be treated with direct moral consideration (DeGrazia 1996). 
The debate about whether animals should be included in the sphere of justice is related to the importance society places on the concept of justice. Justice is enforced by the state and transgressions of justice can be punished by law. Exclusion from the sphere of justice, as Garner has stated, will mean very limited protections for sentient animals (Garner 2013). Sandel discusses the relation of the concept of justice to other moral values:

Justice is not merely one value among others, to be weighed and considered as the occasion arises, but the highest of all social virtues, the one that must be met before others can make their claims (Sandel 1998, p. 48).

According to Cochrane, the incorporation of animals in the sphere of justice means their treatment becomes a "public and political" and not a "private or individual" concern (Cochrane 2010, p. 2). Cochrane relates the idea of justice to the intrinsic value of animals. Extending justice to animals means doing so for the sake of the animals, and not for the sake of society more generally (Cochrane 2010). Cochrane cites the EU Treaty of Lisbon as evidence that we already do include animals in the sphere of justice. Article 13 of the Treaty of Lisbon, which came into force in 2009 and amends the founding EU treaties, states that the Union and member states shall "since animals are sentient being, pay full regard to the welfare requirements of animals". This paper takes the position that sentient animals ought to be, and indeed already are, included within the sphere of justice. If animals ought to be and already are in the sphere of justice, the question becomes what sort of government policies are just?

\section{Virtuous Government}

Some characteristics of a virtuous, i.e. just, government, which mirror those of a virtuous person, can be outlined. A virtuous government considers all sentient animals within its jurisdiction in the sphere of justice. A virtuous government has practical wisdom. To achieve this ideal it consults widely to inform public policy on animals. Thus, a virtuous government strives as far as possible to achieve ideals of democracy and reflect the values of the society it serves.

Virtuous government would be continuously cognisant of the predicament of sentient animals, whereby they cannot directly lobby for their interests to be represented. The virtuous government would therefore be particularly open to claims of government advisory bodies and NGOs which represent the interests of sentient animals. A government's recognition of the power imbalance and susceptibility to unjust exploitation of sentient animals and the full consideration of this in policy formulation would indicate the virtues of beneficence and compassion.

A virtuous government gives particular prominence to the precautionary principle in public policy that impacts sentient animals (FAWC 2011). This means that in policy issues with empirical or moral uncertainty, the benefit of the doubt in competing reasonable claims is given to sentient animals. A virtuous government recognises the inherent limitations of scientific evidence and evidence-based policy generally. Public policy on animals is inherently normative. Scientific and other 
Table 1 Virtues applicable to bovine TB policy

\begin{tabular}{ll}
\hline Category & Virtues \\
\hline Virtues of justice & Justice, fairness, respect, impartiality \\
Virtues of wisdom & Wisdom, understanding, knowledge, discernment \\
Virtues applicable to & Purposefulness, resoluteness, industry, humility, hopefulness, caution, \\
policy making & restraint, moderation, patience \\
Virtues of integrity & Truthfulness, sincerity, honesty, openness, transparency \\
Virtues of loyalty & Loyalty \\
Scientific virtues & Curiosity, trust \\
Virtues of empathy & Empathy, compassion, benevolence, gentleness \\
Virtues of beauty & Beauty, reverence \\
\hline
\end{tabular}

empirical evidence can inform policy on animals, but ethical analysis of policy is essential alongside the interpretation of empirical evidence.

\section{Virtue-Based Analysis of Bovine TB and Badger Control Policy Options}

Some key virtues relevant for bovine TB policy are set out in Table 1.

\section{Bovine TB Policy and Justice}

The first virtue of government is justice (Rawls 1971). Justice is to do with fairness, or giving "to each his due" (Raphael 2001, p. 183). Bovine TB policy can be assessed in the context of fairness and giving each their due. Natural England reported that culling 70,000-100,000 badgers over four years would lead to 2450 fewer herd breakdowns over 9 years (Natural England 2011). ${ }^{2}$ Based on Defra figures (2016), the mean number of cattle slaughtered in high risk bovine TB areas per herd breakdown is 7.25. Hence, around 85,000 (central estimate, $70,000-100,000)$ badgers are culled to prevent the slaughter of 17,763 cattle. Therefore, around five badgers $(85,000 / 17,763=4.785)$ are culled per individual cow that avoids slaughter. These figures assume badgers are culled for the first 4 years of the 9 years. If culling continues in the areas after 4 years, the difference will be greater (McCulloch and Reiss 2017b).

The total cattle population in England is approximately 5.308 million (Defra 2014). The badger population in England has been estimated to be 220,000 (Natural England 2011). Therefore, the slaughter of around 17,763 cattle constitutes killing $0.33 \%$ of the current baseline population in England. The culling of 85,000 badgers constitutes killing $38.6 \%$ of the current baseline population in England. Natural England has estimated the badger population will reduce by $30 \%$ in England and by $50 \%$ in some areas in the south west and west Midlands (Natural England 2011).

\footnotetext{
2 The Natural England report states that these estimates are based on the Donnelly model, which culled badgers over five years with a four year post-culling period. Hence, these estimates are likely to overestimate the benefits of badger culling (Natural England 2011).
} 
(The figure of $38.6 \%$ expressed as a proportion of the baseline population is higher due to reproduction in the badger population.)

Around $33 \%$ of badgers in high bovine TB incidence areas are considered to be infected by $M$. bovis (Donnelly 2013). Therefore, since $67 \%$ of badgers in high risk areas are not infected with $M$. bovis, the majority of badgers culled will be healthy, or at least not infected with bovine TB. In contrast, because cows are tested for $M$. bovis prior to slaughter, most of those slaughtered will be infected with bovine TB. The absolute numbers of badgers and cattle culled, the number of each species expressed as a proportion of the underlying population size, and the disease status of the culled animals all suggest that, in the context of fairness or giving to each their due, badger culling is seriously problematic.

\section{Virtues of Policy Making}

The virtues applicable to policy making can inform policy objectives and policy formulation. Successive British governments have been purposeful, resolute, industrious and hopeful in the aim of bovine TB eradication. For instance, a Conservative government commissioned the Krebs review in 1997. Successive Labour governments oversaw the ISG RBCT which ran from 1998 to 2006. A Labour government set up the Bovine TB Eradication Group (TBEG) in 2006. In 2008 the Secretary of State for Defra, Hilary Benn, announced to Parliament the government's policy to not cull badgers. Benn's speech recognised the limitations of government, stating that although badger culling might work, it might also not work, and it might make the disease situation worse (HC Deb 2008).

The Conservative and Liberal Democratic Coalition government licensed the culling of badgers, against strong public and parliamentary opposition, as well as improving cattle-based measures. The Coalition government had a realistic understanding of bovine TB eradication as a long-term goal (Defra 2011b). Despite this, the Coalition policy of badger culling was arguably not consistent with an appreciation of the limitations of badger culling or patience in attaining the policy objective.

The scientific evidence base, largely provided by the RBCT, concluded that badger culling "cannot meaningfully contribute to the future control of cattle TB in Britain" (Bourne et al. 2007a, p. 14). The British government has claimed it must "use all the tools in the toolbox" (Boyd and Gibbens 2012). However, to develop the government's metaphor, skilled craftspersons use only those tools suited to the task at hand. A blunt hammer is often ill-suited for a complex and delicate job. In bovine TB policy, there is strong evidence to suggest badger culling is not the right tool for the job.

The government's policy to cull badgers cannot be described as moderate, restrained or cautious. It is neither moderate nor restrained, since the policy involves reducing the badger population by up to $50 \%$ in some areas of the country (Natural England 2011). Furthermore, as an AHWBE member rhetorically asked in interview "And do you shoot the right badger when you shoot it?". The government advisor is referring to the fact that around two-thirds of the badgers shot will not be infected with $M$. bovis. The policy is not cautious because there is a serious risk the pilot 
culls may increase, rather than decrease, the incidence of bovine TB in cattle (Bateson et al. 2012; Bourne et al. 2007b).

\section{Curiosity and Trust}

The virtue of curiosity can be interpreted as the endeavour to investigate the science of bovine TB. Such investigation can be construed widely, including investigation of the evidence base and social and economic factors concerned with the disease. The virtue of trust can be interpreted as the faith of successive governments in the evidence base and public opinion. The 1992-1997 Conservative government, the 1997-2010 Labour government, the 2010-2015 Coalition government and the 2015-present Conservative government have all provided funds from the Treasury to fund research into bovine TB.

The Labour government oversaw the ISG RBCT study, consulted public opinion on the principle of badger culling and ruled out a cull in July 2008. The commissioning of the King review in 2007 was significant in the development of bovine TB policy. In contrast to the ISG RBCT, King concluded that culling badgers can contribute to bovine TB control (King 2007). The commissioning of the King review suggests some distrust within Defra of the conclusions of the ISG report.

The question of whether badger culling is an evidence-based policy informs the analysis of whether Defra trusts scientific expertise. The policy issue of bovine TB is sometimes framed as one of a contested science base (Spencer 2011). The science is contested, but disagreements within the scientific community can be overstated. The contradictory findings of the ISG RBCT and the King review are a major reason the science is portrayed as contested. A brief comparison of the approach of the ISG RBCT research and the King review illuminates the sort of evidence on which a virtuous government should base policy.

The ISG RBCT cost $£ 50$ million and ran from 1998 to 2006. The Final report is 289 pages long and includes a substantial amount of data in 84 tables, graphs and other figures, with several hundred scientific references. A large number of peerreviewed papers were published based on the study and a team of independent scientists audited the trial. The King review was written after a single meeting with five experts chosen by the Chief Scientist. King did not consider the economics of culling badgers and restricted his remit to scientific considerations. A Nature editorial was highly critical of the circumstances surrounding the King review in the context of evidence-based policy making:

It would be a good idea if the Department for Environment, Food and Rural Affairs, which is now responsible for the matter, based its policy on the unfettered advice offered by Bourne's committee. This would be deeply appreciated not just by the badgers, but by scientists in all spheres who choose to participate in painstaking advisory processes in the earnest belief that their advice will actually make a difference to government policy (Anon. 2007).

The disagreement between the ISG and the King review led the government to convene a meeting of experts, held at Defra in April 2011. This meeting of experts 
aimed to arrive at some scientific consensus and laid the foundations for the later pilot culls. The key conclusion of the meeting was that culling badgers over $70 \%$ of a $150 \mathrm{~km}^{2}$ land area annually for 4 years, if based on the same methodology of the RBCT, could be expected to reduce the incidence of bovine TB by 12.4-16\% (Defra 2011a). ${ }^{3}$ After the 2011 meeting, two of the experts present (Professor Lord John Krebs and Professor Lord Robert May) signed an open letter to the government urging it to reconsider its policy of culling (Bateson et al. 2012). A third expert present (Professor David Macdonald, Chair of Natural England's Science Advisory Committee) spoke publicly against extending the 2013 pilot culls (Carrington 2013).

During the development of the badger culling policy, John Beddington, the successor to David King as the Chief Scientific Adviser, failed to support the policy. When questioned in 2012 about the policy, Beddington replied "I am content that the evidence base, including uncertainties and evidence gaps, has been communicated effectively to ministers" (Carrington and Doward 2012).

In 2015, Professors John Krebs, John Bourne and Ranald Munro signed an open letter to the government calling on it to halt the badger culls (Bateson et al. 2015). These three individuals chaired the Independent Scientific Review Group (Krebs), Independent Scientific Group (Bourne) and the Independent Expert Panel (Munro). Respectively, these groups advised a randomised culling trial, set up and conducted the RBCT, and audited the subsequent pilot culls. In the context of the government virtues of curiosity and trust, it is seriously problematic for government to reject independent scientific advice when there is a strong consensus between experts from each stage of the scientific investigation.

\section{Integrity and Transparency}

Animal health and welfare policy making should be open, transparent and public. Sentient animals cannot represent their own interests in the policy process. Open, transparent and public processes mitigate the risk of government illegitimately favouring human interests in a way that is not consistent with broader conceptualisations of justice. Furthermore, democratic values mean that policy making in general should be open, transparent and public.

The government has failed to publish relevant information about the impacts of policy on cattle and badgers. It is simply not possible to make policy based on principles of justice, i.e. the right policy, without consideration of the relative impacts of policy on all parties concerned (McCulloch and Reiss 2017a). The key impacts are the number of badgers culled and the number of cattle that would benefit in terms of not being slaughtered. The proportion of badgers infected with M. bovis and the proportion of the population which could be considered to suffer from the disease should also be publicly available information (McCulloch and Reiss 2017b).

In terms of the impact of bovine TB on badgers, Owen Paterson, has claimed in a radio interview that "tens of thousands of badgers are dying hideous deaths from bovine tuberculosis" (Mair 2014). However, based on RBCT data, Jenkins et al.

\footnotetext{
${ }^{3}$ The larger figure of $19 \%$ used in this analysis is based on culling badgers over $350 \mathrm{~km}^{2}$ (Natural England 2011).
} 
have found that only $1 \%$ of infected badgers suffer severe and widespread lesions (Jenkins et al. 2008). This would mean only a few hundred badgers in high incidence culling areas will suffer and eventually succumb to the disease over 4 years (McCulloch and Reiss 2017b).

\section{Loyalty}

The virtue of loyalty has an important role in bovine TB policy. The Conservative Party has traditionally claimed to have a better understanding of the realities of agriculture and to be more supportive of the farming industry compared to Labour ${ }^{4}$ (Conservative Party 2010, p. 2). McEldowney et al. have claimed the Conservative and Liberal Democrat Parties are more sympathetic to badger culling because of their rural voting base (McEldowney et al. 2013, p. 100). Cassidy has reported that right wing newspapers such as The Telegraph are generally supportive of a cull, whilst more left wing papers such as The Guardian are generally opposed (Cassidy 2010).

In interview, a former Defra minister from the Conservative Party denied the suggestion that party political support for badger culling is based on voter considerations [Former Defra minister, Conservative Party]. Despite this, it seems unlikely that TB policy is not influenced by electoral considerations. Indeed, democratic ideals generally suggest that elected parliamentarians represent the views of their constituents.

Whether support for the farming industry is framed as loyalty to constituents or as some other form of loyalty, such as to the food producing role of farmers, there is potential for loyalty to conflict with justice. Since justice is the first virtue of governments, justice should ordinarily override loyalty. In policy making, the virtue of loyalty risks favouring one group over others. In government, the virtue of justice demands that government treats all parties impartially and gives them their due. The moral community includes all human sub-groups as well as sentient animals. In the case of bovine TB, a policy of badger culling that is loyal to the farming community could be unjust when the larger moral community is considered. ${ }^{5}$

\section{Empathy and Compassion}

Badger culling is not consistent with the virtues of empathy, compassion, benevolence and gentleness to badgers. It is sometimes suggested that those opposed to badger culling show compassion and benevolence for badgers, but fail to

\footnotetext{
${ }^{4}$ For instance, a Conservative Party document states: "There is no more important industry than the production of food, but under Labour our farmers have been treated as dispensable" (Conservative Party 2010, p. 2).

5 The prima facie conflict between loyalty and justice is to some extent resolved by distinguishing between the role of the executive and legislative branches of government. The role of a parliamentarian is in large measure to represent the interests of his/her constituents. The primary role of the executive is to make policy based on principles of justice. It follows that ministers have a greater responsibility to make just policy for society at large. In the British political system, ministers retain their role to represent their constituents in Parliament. For this reason, their duties to their constituents and the broader moral community, if they are not aligned, may at times conflict. In such cases, for ministers, duties of justice, based on fairness and impartiality, ought to trump their responsibility to represent their constituents.
} 
show such compassion to cattle slaughtered due to bovine TB [NFU, TB policy official]. Despite this, as discussed in the section on justice, analysis of figures reveals that around five badgers will be culled for every cow that avoids slaughter due to bovine TB infection (McCulloch and Reiss 2017b). Based on equality of consideration, badger culling would be ruled out by compassionate policy.

\section{Aesthetics and Beauty}

It is sometimes claimed that the appearance and literary representation of the badger in English culture influences the bovine TB debate. For instance, in interview a retired civil servant stated:

You know, Mr Badger and Wind in the Willows have done us a lot of damage, a lot of damage, to a rational understanding of the public about animals [Retired civil servant, Defra].

From a virtue perspective, there is nothing intrinsically wrong with aesthetics and literary novels contributing to moral beliefs (Hursthouse 2000). Cassidy has reviewed cultural framings of the badger in British society and found they "have occupied an intensely ambivalent position" (Cassidy 2012, p. 207). For instance, Mr Badger is portrayed in Kenneth Grahame's The Wind in the Willows as a "father figure" and is "intelligent and wise" (Cassidy 2012, p. 203). In contrast, in Beatrix Potter's The Tale of Mr Tod, Tommy Brock uses his cunning to kidnap baby rabbits in a story personifying the natural realities of predation (Cassidy 2012, p. 205). Both Cassidy (2012) and Grant (2009) propose that different framings of badgers need to be considered in bovine TB policy making. This paper agrees with Grant and Cassidy, and indeed argues that a thorough ethical analysis should inform bovine TB and badger control policy.

\section{Conclusion}

Bovine TB is the most economically important animal health policy issue in England. Badgers are a wildlife source of infection but the government's badger culling policy has proven controversial. In this paper, we describe the application of virtue theory, a well-established moral framework, to animal health and welfare policy. A virtue-based analysis, based on the virtues of justice, wisdom, policymaking virtues, integrity, scientific virtues, loyalty, empathy and aesthetics has been applied to bovine TB and badger culling.

Justice is the first virtue of government, and the analysis has found badger culling to be problematic in this context. Based on government figures of achieving a $19 \%$ reduction bovine TB incidence over 9 years, around 85,000 badgers will be culled to prevent the slaughter of approximately 18,000 cattle. This translates to around five badgers culled for each cow that avoids slaughter. Furthermore, whereas slaughtering $\sim 18,000$ cattle involves killing $0.33 \%$ of the baseline cattle population, culling $\sim 85,000$ badgers involves killing $38.6 \%$ of the baseline badger 
population. These figures are based on optimistic estimates of the positive impacts of badger culling. Given the Independent Scientific Panel (ISP) recommendations against culling, and the failures highlighted by the Independent Expert Group (IEG) in the pilot culls, it is likely that the benefits of culling, if indeed there are benefits, will be of a much smaller magnitude.

Broadly, analysis of other virtues applicable to the issue found the government's badger culling policy to be problematic. For instance, badger culling-given moral harms associated with killing, inevitable suffering caused by suboptimal shooting, and the potential for perturbation, thus worsening the disease in both species-is neither cautious, moderate nor restrained. Badger culling is not consistent with empathy, compassion or benevolence. Furthermore, the 2010 Coalition and the 2015 Conservative government's badger culling policy rejected the recommendations of the ISG, based on the $£ 50$ million, 8-year RBCT, favouring less rigorous forms of evidence such as the subsequent King review and evidence from experience in other countries, mostly with wildlife species other than the badger.

Acknowledgements The first author would like to thank the Royal Veterinary College, University of London, which funded work for a Ph.D. that this paper is based on. He would also like to thank the animal health and welfare policy actors interviewed during the course of the research. Finally, we would like to thank the late Christopher Wathes, who was one of the first author's Ph.D. supervisors.

Open Access This article is distributed under the terms of the Creative Commons Attribution 4.0 International License (http://creativecommons.org/licenses/by/4.0/), which permits unrestricted use, distribution, and reproduction in any medium, provided you give appropriate credit to the original author(s) and the source, provide a link to the Creative Commons license, and indicate if changes were made.

\section{References}

Anon, J. (2007). In for the cull. Nature, 450(7166), 1-2.

Bateson, P., Begon, M., Blackburn, T., Bourne, J., Sutherland, W., Burke, T., \& Woodroffe, R. (2012). Culling badgers could increase the problem of TB in cattle: Badger culling risks becoming a costly distraction from nationwide TB control. The Observer. Retrieved from http://www.theguardian.com/ theobserver/2012/oct/14/letters-observer?guni=Article:in\%20body\%20link.

Bateson, P., Krebs, J., Bourne, J., Munro, R., Sillero, C., Crispin, S., \& Bayley, J. (2015). Badger cull is flawed and must now stop. The Guardian. Retrieved from https://www.theguardian.com/uk-news/ 2015/sep/02/badger-cull-is-flawed-and-must-now-stop.

Bourne, F. J., Donnelly, C. A., Cox, D. R., Gettinby, G., McInerney, J. P., Morrison, W. I., \& Woodroffe, R. (2007a). Bovine TB: The scientific evidence - final report of the Independent Scientific Group on Cattle TB. London: Independent Scientific Group on Cattle TB.

Bourne, F. J., Donnelly, C. A., Cox, D. R., Gettinby, G., McInerney, J. P., Morrison, W. I., \& Woodroffe, R. (2007b). Response to "Tuberculosis in Cattle and Badgers: A report by the Chief Scientific Adviser". London: Former members, Independent Scientific Group on Cattle TB.

Boyd, I., \& Gibbens, N. (2012). Badger cull furore is distracting attention from the real problem. The Guardian. Retrieved from http://www.theguardian.com/environment/2012/oct/11/badger-cullfurore.

Carrington, D. (2013). Stop badger cull immediately, says Natural England science expert. The Guardian. Retrieved from http://www.theguardian.com/environment/2013/oct/21/stop-badger-cull-immediatelynatural-england-scientist. 
Carrington, D., \& Doward, J. (2012). Badger cull 'mindless', say scientists. The Guardian. Retrieved from http://www.theguardian.com/environment/2012/oct/13/badger-cull-mindless.

Cassidy, A. (2010). Badgers and bovine TB: Coverage of a messy science/policy controversy in the UK press. Paper presented at the Bovine Tuberculosis: People, Politics and Culture Workshop, University of Warwick. www2.warwick.ac.uk/fac/cross_fac/gld/bovine_tuberculosis_workshop_ 01_info.pdf.

Cassidy, A. (2012). Vermin, victims and disease: UK framings of badgers in and beyond the bovine TB controversy. Sociologia Ruralis, 52(2), 192-214.

Cochrane, A. (2010). An introduction to animals and political theory. Basingstoke: Palgrave Macmillan.

Conservative Party. (2010). A new age of agriculture: Our agenda for British farming. London: Conservative Party.

Defra. (2011a). Bovine TB - Key conclusion from the meeting of scientific experts, held at Defra on 4th April 2011. London: Defra.

Defra. (2011b). Bovine TB eradication programme for England. London: Defra.

Defra. (2011c). The Government's policy on bovine TB and badger control in England. London: Defra.

Defra. (2014). Farming Statistics - Livestock Populations at 1 December 2013, England. London: Defra Retrieved from https:/www.gov.uk/government/uploads/system/uploads/attachment_data/file/ 286876/structure-dec2013-eng-06mar14.pdf.

Defra. (2016). Further measures to eradicate bovine TB [Press release]. Retrieved from https://www.gov. uk/government/news/further-measures-to-eradicate-bovine-tb.

Defra, \& GSS. (2016). Quarterly publication of national statistics on the incidence and prevalence of tuberculosis (TB) in cattle in Great Britain - to end June 2016. London: Office for National Statistics.

DeGrazia, D. (1996). Taking animals seriously: Mental life and moral status. Cambridge: Cambridge University Press.

Donnelly, C. (2013). The badger cull-key science questions answered. The Guardian. Retrieved from http://www.theguardian.com/environment/2013/oct/11/badger-cull-key-science-questionsanswered.

FAWC. (2011). Economics and farm animal welfare. London: Farm Animal Welfare Committee.

Garner, R. (2013). A theory of justice for animals: Animal rights in a nonideal world. Oxford: Oxford University Press.

Grant, W. (2009). Intractable policy failure: The case of bovine TB and badgers. The British Journal of Politics \& International Relations, 11(4), 557-573.

HC Deb. (2008). Bovine TB. Hansard, 478(col. 1153).

Hursthouse, R. (2000). Ethics, humans and other animals: An introduction with readings. London: Routledge.

Hursthouse, R. (2013). Virtue Ethics. Stanford Encyclopedia of Philosophy. Fall 2013 Edition. Retrieved 3 February, 2015, from http://plato.stanford.edu/archives/fall2013/entries/ethics-virtue/.

IEP. (2014). Pilot badger culls in somerset and gloucestershire: Report by the Independent Expert Panel. London: Independent Expert Panel.

Jenkins, H. E., Morrison, W. I., Cox, D. R., Donnelly, C. A., Johnston, W. T., Bourne, F. J., et al. (2008). The prevalence, distribution and severity of detectable pathological lesions in badgers naturally infected with Mycobacterium bovis. Epidemiology and Infection, 136(10), 1350-1361.

King, D. (2007). Bovine tuberculosis in cattle and badgers. London: Defra.

Krebs, J. R., Anderson, R., Clutton-Brock, T., Morrison, I., Young, D., \& Donnelly, C. (1997). Bovine tuberculosis in cattle and badgers. London: Independent Scientific Review Group.

Mair, E. (2014). Coverage and analysis of the day's news. PM: BBC Radio 4.

McCulloch, S. P., \& Reiss, M. J. (2017a). Bovine tuberculosis and badger control in England: Science, policy and politics. Journal of Agricultural \& Environmental Ethics.

McCulloch, S. P., \& Reiss, M. J. (2017b). The development of an Animal Welfare Impact Assessment (AWIA) tool and its application to bovine tuberculosis and badger control in England. Journal of Agricultural \& Environmental Ethics. doi:10.1007/s10806-017-9684-5.

McEldowney, J., Grant, W., \& Medley, G. (2013). The regulation of animal health and welfare: Science, law and policy. Abingdon: Routledge.

Natural England. (2011). The impact of culling on badger (Meles meles) populations in England and measures to prevent their 'local disappearance' from culled areas: Supplementary advice provided under the Protection of Badgers Act 1992 and Wildlife \& Countryside Act 1981 (as amended): Natural England.

Raphael, D. D. (2001). Concepts of justice. New York: Clarendon Press. 
Rawls, J. (1971). A theory of justice (1st ed.). Massachusetts: Harvard University Press.

Sandel, M. J. (1998). Liberalism and the limits of justice. Cambridge: Cambridge University Press.

Sandel, M. J. (2010). Justice: What's the right thing to do?. London: Penguin Books.

Spencer, A. (2011). One body of evidence, three different policies: bovine tuberculosis policy in Britain. Politics, 31(2), 91-99. 